\title{
The Beta Amyloid Dysfunction (BAD) Hypothesis for Alzheimer's Disease
}

\author{
Heinz Hillen* \\ Independent Researcher, Haßloch, Germany
}

Beta amyloid, A $\beta$ 1-42, originally named as Amyloid A4 protein, is one of the most investigated peptides in neuroscience and has attracted substantial interest since its discovery as the main insoluble fibril-type protein in cerebrovascular amyloid angiopathy (Glenner and Wong, 1984; Masters et al., 1985) of Alzheimer's disease (AD). From the very beginning, A $\beta$ was regarded per se as a "bad molecule," triggering the so-called "beta amyloid cascade hypothesis" (Hardy and Higgins, 1992). This hypothesis ignored any physiological function for in situ generated $A \beta$ monomer with normal production and turnover rate (Bateman et al., 2006). Accordingly, pan-A $\beta$-related therapeutic approaches were designed to eliminate or lower the three structural isoforms in parallel: (1) the pre-amyloid monomer, (2) the misfolded oligomer, and (3) the final fibril. While we already knew about poor correlations between plaques and cognitive decline quite early (Terry et al., 1991), data for an essential benign physiological role for $A \beta$ monomer at low concentrations were also not considered to be relevant. Here, a different Beta Amyloid hypothesis is described, the so-called "Beta Amyloid Dysfunction hypothesis," which, in contrast to the "Beta Amyloid Cascade hypothesis," builds on the homeostasis of essential A $\beta$ monomer in the synaptic vesicle cycle (SVC). Diseaserelevant early pathology emerges through disturbance of the $A \beta$ homeostasis by so far unknown factors leading to the formation of misfolded $A \beta$ oligomers. These early species interfere with the synaptic physiological $A \beta$ monomer regulation and exert their neurotoxicity via various receptors for sticky oligomer-type $A \beta$ aggregates. The Beta Amyloid Dysfunction (BAD) hypothesis is introduced and shown to explain negative clinical results of Gamma-secretase and Beta-secretase (BACE) inhibitors as well as pan- $A \beta$ isotype unselective immunotherapies. This hypothesis gives guidance to what needs to be done therapeutically to revive successful clinical testing in AD for this highly validated target. The BAD hypothesis will need further refinement in particular through more detailed exploration for the role of physiological $A \beta$ monomer.

\section{Keywords: amyloid beta protein, therapy, Alzheimer's disease (AD), vaccination, hypothesis}

\section{INTRODUCTION}

$A \beta$ and in particular $A \beta 1-42$ so far has been the main target molecule pursued by the pharmaceutical industry to achieve disease-modifying treatments in Alzheimer's disease (AD). Genetic exploration of its amyloid precursor protein (APP) (Dyrks et al., 1988) and processing by Beta-secretase (BACE; Vassar et al., 1999) and Gamma-secretase complexes PSEN1 and PSEN2 (Wolfe et al., 1999) have led to a basic molecular understanding of its bioprocessing.

Mutations in PSEN and APP genes in rare cases of Familiar Alzheimer's Disease (FAD) (St George-Hyslop and Petit, 2005) either result in aberrant amyloid beta production 
or lead to an unfavorable shift in $\mathrm{A} \beta 40 / \mathrm{A} \beta 42$ ratio and in some cases to increased $A \beta$ production (Weggen and Beher, 2012). Altogether, the variety of different mutations give substantial evidence for the validation of $\mathrm{A} \beta$ as a valuable target in $\mathrm{AD}$.

A long series of clinical disappointments starting with an aggregated A $\beta$ AN-1792 Active Immunization study (Bayer et al., 2005; Nicoll et al., 2019) in 2001 up to recent failures of various BACE inhibitors (Panza et al., 2018; Egan et al., 2019) and two gamma secretase inhibitors (Coric et al., 2012; Doody et al., 2013) have created substantial doubts about the underlying Amyloid Cascade hypothesis (Hardy and Higgins, 1992). From the protagonists of the Cascade hypothesis, the most obvious reason for clinical failure could be the very early onset of $\mathrm{A} \beta$ pathology. This may only be partly true, since it does not explain the shared cognitive side effects for structurally diverse Gamma- and beta-secretase inhibitors in clinical testing. The main discussion here is focused on limitations of individual clinical candidates rather than questioning the validity of the underlying hypothesis. The majority of scientists still look at "Amyloid beta" as a homogeneous target and have not incorporated the variety of biology between the in vivo existing three major and very different protein assemblies, all of them named "A $\beta$," albeit they only share the primary amino acid sequence. These are (1) A $\beta$ monomer, (2) misfolded soluble $A \beta$ oligomers, and (3) fibrillar $A \beta$.

The $A \beta$ field has suffered from a persisting undistinguished isotype terminology in most scientific papers. In order to enable a precise understanding of the new Beta Amyloid Dysfunction (BAD) hypothesis, this article will try to clarify upfront some definitions on the three different " $\mathrm{A} \beta$ " forms.

\section{DEFINITIONS OF A $\beta$ ISOFORMS}

Figure 1 illustrates the three fundamental structural forms that are known for "A $\beta$ " and key features we know in terms of structural core elements characteristic for oligomer- and fibriltype $A \beta$.

\section{A $\beta$ Monomer}

$\mathrm{A} \beta$ is generated in synaptic processes at relatively high production and turnover rates (Bateman et al., 2006). It is released as $\mathrm{A} \beta$ monomer by activated neurons (Cirrito et al., 2008) and has been shown to modulate synaptic activity in a timeand concentration-dependent manner (Kamenetz et al., 2003; Abramov et al., 2009). A $\beta$ dynamics correlate with neurological status in acute brain injury (Brody et al., 2008). From a physicochemical perspective, the $A \beta$ monomer belongs to the class of intrinsically disordered proteins (IDP) that lack a fixed three-dimensional structure (Oldfield and Dunker, 2014). A $\beta$ is metastable in aqueous solutions and gains stability by forming secondary structure in membrane-like environment (Morgan et al., 2004). Hence, unlike its precursor APP, we do not have solid experimental data on instable nascent $A \beta$ monomer in particular outside the CSF compartment. It is suggested that $A \beta$ monomer $A \beta 1-40$ and $A \beta 1-42$ upon well-controlled release by BACE- and Gamma-secretase are essential facilitating molecules to contribute to synaptic vesicle cycling in neurons (Cirrito et al., 2008; Ovsepian et al., 2018). CSF A $\beta$ is almost perfectly monomeric, since oligomeric and fibril-type $A \beta$ species are below detection limits of conventional bioassays (Rosén et al., 2013). Recently, ultrasensitive tests have been described that claim detection of aggregated $\mathrm{A} \beta$ in human CSF of $\mathrm{AD}$ patients, but these are not fully validated (Salvadores et al., 2014; Yang et al., 2015) so far. Although monomeric $A \beta$ and in particular A $\beta 1-42$ is highly prone to aggregate, folding control through chaperones normally guarantees a precise control of biosynthesis and physiological turnover in non-diseased young and most older human beings. Significant levels of aggregated protein species with high molecular weight would create a substantial increase in viscosity and could not be tolerated in thin CSF. Decreasing CSF A $\beta 42$ monomer levels is one of the earliest and best biomarker for patients with mild cognitive impairment (MCI) or AD.

\section{Misfolded A $\beta$ Oligomers}

Misfolded $A \beta$ oligomers are defined as any $A \beta$ species that undergoes structural transformation into at least dimers or multimers, thereby changing its 3D structure into detergentsoluble amyloid $\mathrm{A} \beta$ species. While nascent monomers in healthy individuals undergo complete physiological processing, oligomers bind to a number of proteins and receptors (Cline et al., 2018). The common denominator for all early $A \beta$ oligomers $A \beta x-y$ is a characteristic epitope in the middle part of the peptide (AA17-AA33). This epitope is different in fibril-type $A \beta$ and not available in nascent $A \beta$ monomers (Yu et al., 2009). The definition by a common epitope is more helpful compared to a classification by size or peptide modification $(A \beta x-y)_{n}$. Following the epitope definition, smaller fragments with a fibriltype core structure should not be included here and named as preforms of fibrils, i.e., protofibrils. Though in many papers the name protofibrils is often used as synonym for $A \beta$ oligomers which leads to confusion. The majority of $\mathrm{AD}$ brain deposited $\mathrm{A} \beta$ oligomers can be precisely characterized next to monomer and fibrils through immunoprecipitation by immobilized $A \beta$ oligomer isotope selective antibodies from $\mathrm{AD}$ brains and subsequently in a separate step quantified independently as $A \beta x-y$ oligomers (Hillen et al., 2010).

In contrast to fibril-type $\mathrm{A} \beta$, all misfolded $\mathrm{A} \beta$ oligomers from in vivo brains dissolve in SDS-containing buffers.

It should also be mentioned here that every monomeric protein displays some minimal reversible equilibrium with its non-misfolded dimeric form. Due to this effect, in some test settings, e.g., like symmetric ELISAs, $A \beta$ oligomer data might be misinterpreted in terms of detection of traces of misfolded $A \beta$ in human fluids, like CSF or plasma.

\section{A $\beta$ Fibrils}

$\mathrm{A} \beta$ fibrils were the first $\mathrm{A} \beta$ isoform discovered as "Amyloid beta, A4" in brains of AD patients (Glenner and Wong,1984). The regular structure of $\mathrm{A} \beta$ fibrils is well defined and stable (Petkova et al., 2002). Fibrils can nicely grow by adding $A \beta$ monomer but not by adding $A \beta$ oligomers (Gellermann et al., 2008), indicating that the oligomers are not direct intermediates on the folding pathway of fibrils. Fibril-type structures are clearly distinguishable from oligomer-type $A \beta$ via solid-state NMR or by 

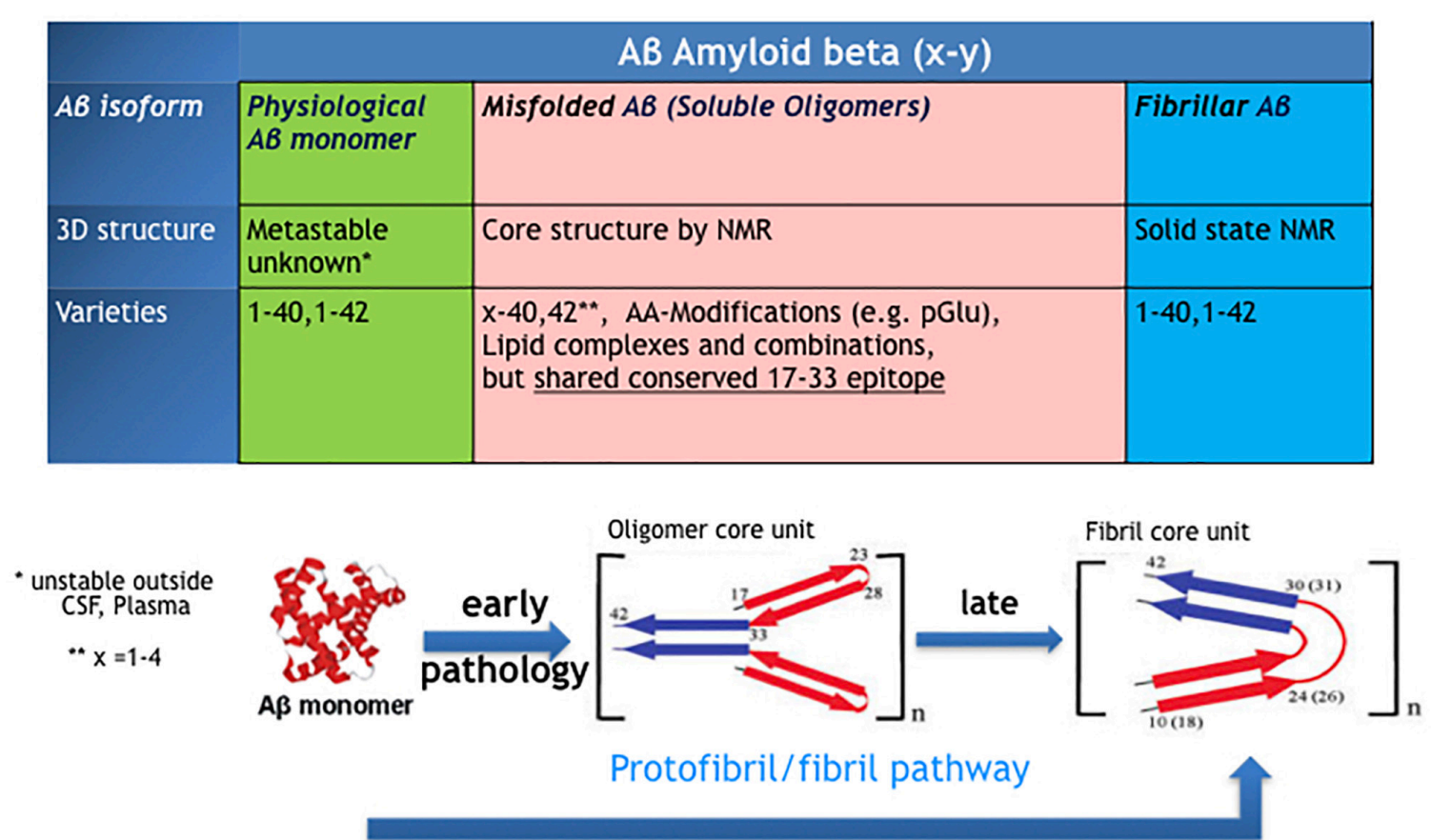

- Categorizing between ,the physiological $A B$ monomer“" ",the early
neurotoxic $A B$ (soluble oligomers)“ and "the fibril type $A B$ (plaques)“

FIGURE 1 | The confusion around the peptide "Amyloid beta, A $\beta$." Three very different types of protein assemblies sharing the same name.

highly oligomer selective antibodies (Yu et al., 2009; Hillen et al., 2010; Lu et al., 2013).

Fibrils are the main $\mathrm{A} \beta$ form in plaques and, in contrast to detergent-soluble $\mathrm{A} \beta$ oligomers, can only be dissolved in formic acid.

\section{THE BETA AMYLOID DYSFUNCTION HYPOTHESIS}

\section{A $\beta$ Monomer Homeostasis Is Essential for Synaptic Function}

$\mathrm{A} \beta$ biogenesis and turnover is an essential physiological process conserved in neurons of vertebrates. The central point of difference between the old $\mathrm{A} \beta$ Cascade hypothesis and the new Dysfunction hypothesis is the claim for a physiological role of the $\mathrm{A} \beta$ monomer in non-diseased individuals. There is multiple evidence that $A \beta$ monomer plays an important role in synaptic activity regulation (Cirrito et al., 2005; Abramov et al., 2009; Morley et al., 2010). The group of Copani has suggested that the "loss-of-function" hypothesis for the role of $A \beta$ in neurons should be taken into consideration (Giuffrida et al., 2009). The homeostasis of synaptic $A \beta$ monomer levels is critical and extremely complex. The complexity of $A \beta$ monomer physiology is due to the interplay of a metastable hydrophobic peptide with membranes, lipids, and vesicles. Quantifying metastable
$\mathrm{A} \beta$ monomer concentrations in living organisms is challenging since IDPs can adopt their structure upon extraction. While there has been some success with a combination of synchrotronbased Fourier transform infrared micro-spectroscopy and nondenaturing gel electrophoresis to characterize intermediate A $\beta$ species in APP TG mice (Klementieva et al., 2017), it remains extremely difficult to determine nascent $A \beta$ monomer concentrations in vivo.

It can only be postulated that $\mathrm{A} \beta$ pathophysiology is assumed to start, when the formation and metabolism process is disturbed. Table 1 summarizes key papers supporting the physiological $\mathrm{A} \beta$ role.

Impairment of the $A \beta$ turnover process results in early generation of misfolded neuropathogenic species on cost of synaptic physiological A $\beta$ levels. The BAD hypothesis of $\mathrm{AD}$ predicts that both effects synergize and contribute to early pathology via two mechanisms: $A \beta$ oligomer-type neuropathogenic species bind to various receptors mediating cell toxic effects (Lauren et al., 2009; Ohnishi et al., 2015) and secondly disturbance of $\mathrm{A} \beta$ monomer homeostasis at synaptic sites through $A \beta$ oligomer formation. If we consider optimal monomer concentration at the synapse to be a critical factor, replenishment upon loss of $\mathrm{A} \beta$ monomer is immediately needed. This can only be achieved by increased production of $A \beta$ via APP processing and BACE up-regulation. Through this positive feedback loop, an additional risk of misfolding by enhanced $A \beta$ monomer production and turnover is created. The best indicator 
TABLE 1 | Key findings to the essential role of $A \beta$ monomer in physiological synaptic processes.

\begin{tabular}{|c|c|c|}
\hline Item & Key data & Paper \\
\hline Synaptic processes & $\begin{array}{l}\text { - Endogenously released } A \beta \text { peptides regulate synaptic transfer at single pre-synaptic terminals and } \\
\text { synaptic connections in rodent hippocampal cultures and slices }\end{array}$ & Abramov et al., 2009 \\
\hline Synaptic activity & - Inhibiting neuronal activity by TTX decreases ISF A $\beta$ levels & Cirrito et al., 2008 \\
\hline Learning and memory & $\begin{array}{l}\text { - Low doses of icv administered monomeric A } \beta \text { improves cognitive behavior in non TG mice } \\
\text { - Anti monomer A } \beta \text { antibody impairs cognitive behavior in non TG mice } \\
\text { - A } \beta \text { monomer is essential for LTP } \\
\text { - Impaired learning by anti sense A } \beta\end{array}$ & Morley et al., 2010 \\
\hline Cortical neurons & $\begin{array}{l}\text { - A } \beta \text { production is critical for viability of neurons } \\
\text { - } A \beta \text { monomer is neuroprotective }\end{array}$ & $\begin{array}{l}\text { Plant et al., } 2003 \\
\text { Giuffrida et al., } 2009\end{array}$ \\
\hline APP KO mice & $\begin{array}{l}\text { - Impaired LTP } \\
\text { - Poor performance in spatial memory tasks } \\
\text { - Reduced synapses }\end{array}$ & $\begin{array}{l}\text { Dawson et al., } 1999 \\
\text { and Seabrook et al., } 1999\end{array}$ \\
\hline PS1 deficient mice & $\begin{array}{l}\text { - Reduced A } \beta \text { levels } \\
\text { - Impaired LTP }\end{array}$ & Morton et al., 2002 \\
\hline
\end{tabular}

for this effect is elevation of BACE in CSF of AD patients (Zetterberg et al., 2008; Decourt and Sabbagh, 2011) as well as in pre-synaptic terminals of TG models of AD (Zhang et al., 2009).

Early biochemical deviations from $A \beta$ physiology in MCI are indicated by lowered CSF A $\beta 42$ monomer already before substantial loss of neurons occurs in later stages of $\mathrm{AD}$ (Fagan et al., 2009).

Monomeric A $\beta$ can be regarded as a benign pre-amyloid peptide that serves as a permanent source for an essential physiological cofactor needed in the synaptic vesicle cycle (SVC) process (Südhof, 1995). The SVC is known to be the primary site for $A \beta$ production enriched in pre-synaptic terminals (Thinakaran and Koo, 2008; Müller et al., 2017). So far, the data for potential $A \beta$ monomer involvement in SVC's turnover were discussed either as contributions by the precursor molecule APP or in the context of pathophysiology only. In analogy to research on synuclein, where the molecular differences between physiological and pathophysiological isoforms are better understood (Burré et al., 2014), we still need more efforts to explore the details of a potential physiological role for $A \beta$ monomer in binding proteins in the course of synaptic vesicle formation and exchange.

Once we have agreed to claim a physiological role for $\mathrm{A} \beta$ monomer and to categorize the $\mathrm{A} \beta$ structural isoforms in the three different buckets $A \beta$ monomer, early misfolded $\mathrm{A} \beta$ oligomers and $\mathrm{A} \beta$ fibrils, the next step is to look at how these forms in terms of physiology and pathophysiology are connected and interdependent. In the next four paragraphs, the fundamental concept of the BAD hypothesis will be laid out.

\section{A $\beta$ Bioprocessing in Phases of Physiology, Pathophysiology, and Therapeutic Recovery}

\section{Part 1. The Physiological $A \beta$ Production and Turnover}

There is substantial evidence about a physiological role of $A \beta$ monomer summarized and reviewed by Copani (2017). A $\beta$ production and turnover have been determined in human CSF in vivo by 7.6 and $8.3 \% / \mathrm{h}$, respectively (Bateman et al., 2006).
These values are exceptionally high and reflect the challenge for a difficult protein to be maintained in a correct shape under folding control in vivo. Using the Stable Isotope Labeled Kinetics (SILK) technology, Bateman has demonstrated that $\mathrm{A} \beta$ turnover is changed in $\mathrm{AD}$ and slows down by age about 2.5 fold (Patterson et al., 2015). A $\beta$ concentrations are highly regulated at synaptic sites (Figure 2A). This comprises the well-controlled Gammaand beta-secretase activities that together ensure optimal synaptic $\mathrm{A} \beta$ monomer concentrations according to the individual neuron activity needed.

\section{Part 2. The Early Pathophysiological $A \beta$ Process}

It is common knowledge now that $A \beta$ pathology based on misfolding in brains precedes cognitive deficits in $\mathrm{AD}$ by more than a decade (Blennow et al., 2015). The earliest measurable A $\beta$ parameter indicating $\mathrm{A} \beta$ pathology in $\mathrm{MCI}$ and $\mathrm{AD}$ patients is a lowered A $\beta$ monomer1-42 CSF level. This decrease of the earliest $\mathrm{A} \beta$ marker reflects the start of an impairment in physiology, at a time when $\mathrm{A} \beta$ monomer escapes at least partly the in vivo folding control. While, in FAD, it can be assumed that chaperone control will be exhausted through APP mutations or overproduction at a certain point in time, it is unknown what triggers the beginning of oligomer formation in sporadic AD. In the early phase of MCI, $\mathrm{A} \beta \mathrm{x}-\mathrm{y}$ oligomers with a characteristic structure on the typical oligomer folding pathway (Yu et al., 2009; Hillen et al., 2010) can be detected by oligomer selective antibodies (Figure 2B). These sticky molecules can bind promiscuously to many proteins and cell surface receptors, e.g., the PrPc protein (Smith and Strittmatter, 2017) or RAGE (Yan et al., 1996). Oligomers also impair the high neuronal energy consumption by binding to key mitochondrial proteins (Reddy and Beal, 2008). The deleterious effects of $\mathrm{A} \beta$ oligomers have been widely described and reviewed in the last two decades (Cline et al., 2018).

\section{Part 3. Compensation Worsens Pathology}

Besides the synaptotoxicity of oligomers via potential receptormediated effects, early $A \beta$ monomer misfolding leads to a deficiency of $\mathrm{A} \beta$ monomer at the synapse. Assuming that neuronal activity-associated $A \beta$ monomer concentration is an 
A

1.Physiology
AB monomer homeostasis at synaptic terminals ensures optimal
synaptic activity

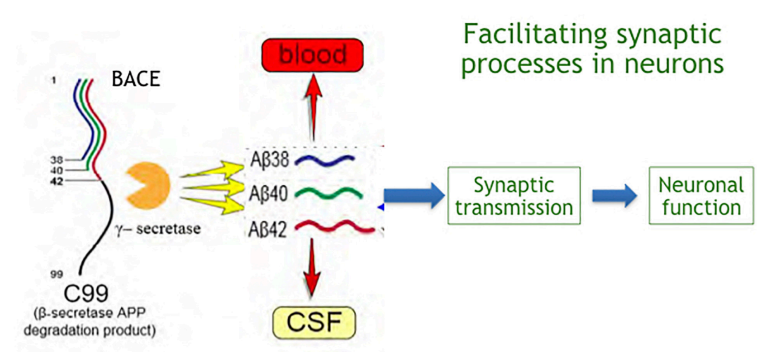

$A B$ pool in CSF is gold standard for clean $\mathrm{AB}$ monomer

B

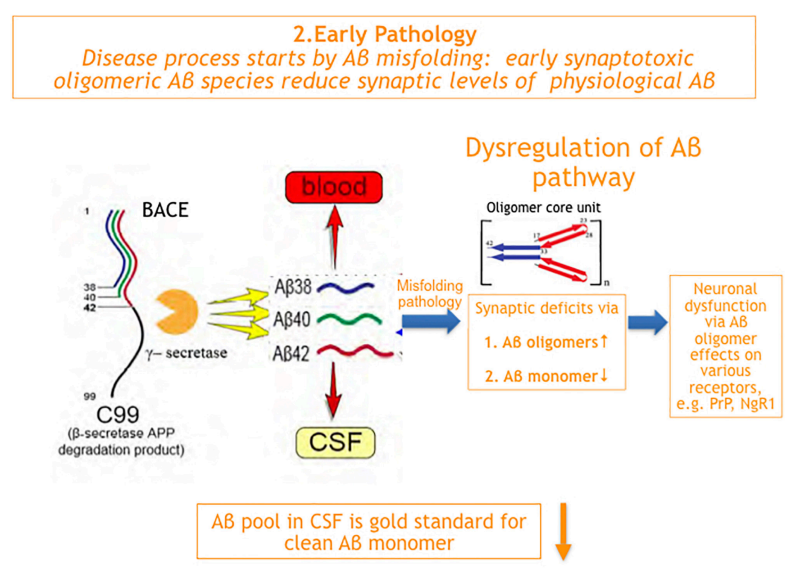

C

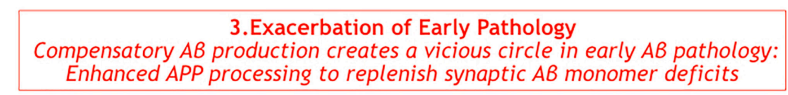

Enhanced APP processing to replenish synaptic $A B$ monomer deficits

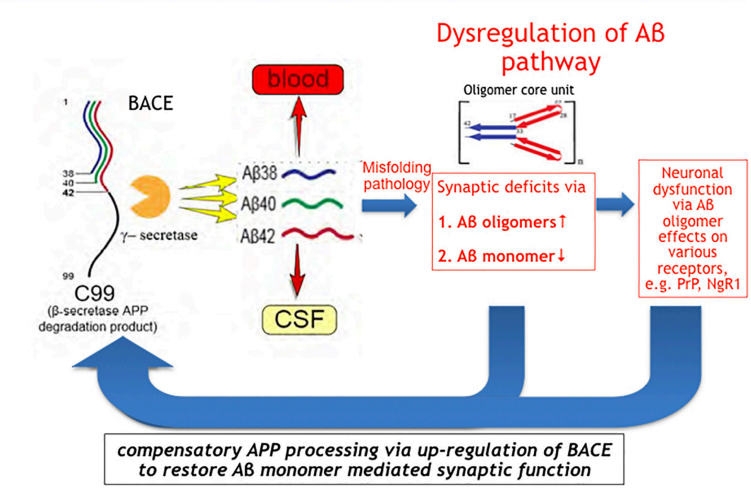

D

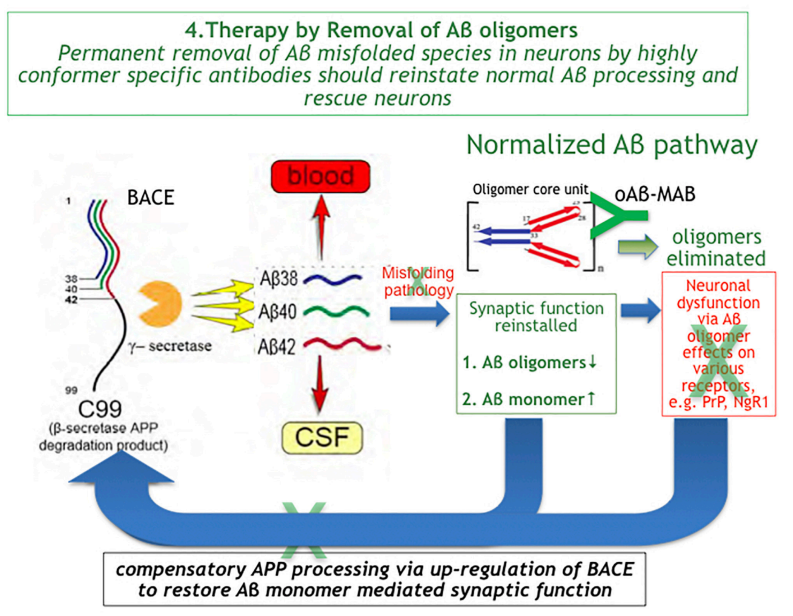

FIGURE 2 | The Beta Amyloid Dysfunction Hypothesis (BAD). (A) Part 1. The Beta Amyloid physiological process [fragments of graphics in panels (A-D) were taken from Patterson et al. (2015)]. In normal individuals, $A \beta$ monomer is produced, metabolized, and replaced at high rates without formation or residual aggregates. (B) Part 2. The Beta Amyloid pathophysiological process begins. A $\beta$ monomer folding control is becoming imperfect and A $\beta$ oligomers begin to form on cost of monomer concentration at synaptic sites. While, in FAD, exhaustion of chaperones can be assumed as the main trigger for pathology, the reason in sporadic $A D$ is unknown so far. (C) Part 3. Exacerbation of pathology through positive feedback loop. In order to maintain $A \beta$ monomer homeostasis, the loss of $A \beta$ monomer induces increased $A \beta$ production by BACE up-regulation, which exacerbates $A \beta$ misfolding rate: a vicious cycle. (D) Part 4. A $A$ oligomer selective immunotherapy reverses $A \beta$ dysregulation by removal of misfolded species (OA $\beta-M A B=$ selective anti $A \beta$ oligomer monoclonal antibody).

essential factor in modulating synaptic activity means to demand a compensation for Abeta monomer losses by BACE upregulation. This could happen in a typical positive feedback loop. As a consequence of increased $A \beta$ production, the misfolding rate continues to increase (Figure $2 \mathrm{C}$ ). Hence, a vicious cycle of enhanced $A \beta$ production and turnover exacerbates the $A \beta$ pathology via increased oligomer formation and monomer deficiency in parallel.

Beta-secretase up-regulation upon $A \beta$ monomer deficiency is not confirmed directly by data so far. But there is quite some evidence that BACE regulation is an extremely sensitive and early process tightly linked to pre-synaptic APP regulation. Like A $\beta$ monomer reduction in CSF, increase of BACE1 activity is a very early biomarker of $\mathrm{A} \beta$ pathology in MCI and early $\mathrm{AD}$ (Zhong et al., 2007). BACE1 gene expression is elevated in sporadic AD
(Fukumoto et al., 2002; Holsinger et al., 2002; Li et al., 2004). Synaptic BACE1 is colocalized with APP in the same vesicle (Steuble et al., 2012; Deng et al., 2013).

Substantial evidence for an existing feedback loop between $\mathrm{A} \beta$ oligomers and $A \beta$ regulation is derived from oligomer binding to Nogo-66 receptor1 (NgR1), which has been shown to regulate APP processing (Smith and Strittmatter, 2017).

\section{Part 4. Early $A \beta$ Oligomer-Type Therapy Reverses $A \beta$ Dysregulation}

Following this concept, the therapeutic strategy should be reversing the pathology by removing the misfolded $A \beta$ species in time in situ at neuronal sites as illustrated in Figure 2D. The most specific way of doing this would be a potent and sufficiently CNSpenetrant $A \beta$ oligomer-directed selective immunotherapy by an 
individual antibody or a corresponding Active Immunization regimen. This should normalize $A \beta$ turnover and consequently the biomarkers $\mathrm{A} \beta 42$ and $\mathrm{BACE}$ in CSF are expected to normalize as well. A potential co-therapy would be a combination with a pure Gamma secretase modulator, to reduce $A \beta$ aggregation propensity by increasing $A \beta 38$ and $A \beta 40$ on cost of $A \beta 42$ levels.

\section{The Pathology Starts in the Neuron}

It is often argued that $A \beta$ is an extracellular protein and cannot contribute to $A \beta$ oligomer pathology inside the neuron. But there is multiple evidence that soluble misfolded $A \beta$ species accumulate in the cell and disturb the physiological $\mathrm{A} \beta$ processing (Philipson et al., 2009; Youmans et al., 2012; Antonios et al., 2013; Zhao et al., 2014). The evidence for intraneuronal Abeta pathology is an additional argument for the interference of $A \beta$ oligomers with potential A $\beta$ monomer-mediated SVC formation and exchange processes in neurons.

\section{DISCUSSION}

\section{Cascade Hypothesis Versus Dysfunction Hypothesis}

The BAD hypothesis is able to explain findings that are left unexplained by the Cascade hypothesis. Table 2 summarizes key major items that follow the rules of the BAD hypothesis but not the Cascade hypothesis.

The plausibility for a physiological role of a highly expressed and high-turnover pre-amyloidogenic protein like the $A \beta$ peptide is already given through analogy with other CNS proteins like synuclein and tau, which are known to have a structural isoform associated with a benign physiological function (Guo et al., 2017; Burré et al., 2018). According to the Cascade hypothesis, the $A \beta$ formation is regarded as a superfluous relic left by evolution. But $A \beta$ homeostasis in brains is an extremely well-regulated and energy-consuming process in normal human brains. Eliminating the generation of this central protein in $\mathrm{AD}$ therapy therefore seems to lack plausibility.

Another strength of the BAD over the Cascade hypothesis is that it defines the critical neurotoxic $A \beta$ species as a molecule deviating structurally from the monomer in its earliest point in time, which does not leave the toxicity to very lately formed and highly insoluble inert fibril species in plaques. This concept is in line with observations that, (1) $A \beta$ pathology and oligomer formation is detected very early and (2) plaques do not well correlate with $\mathrm{AD}$. According to the $\mathrm{BAD}$ hypothesis, reduced monomeric CSF A $\beta$ is the earliest indicator of started misfolding of $A \beta$ in neurons. Finally, misfolded $A \beta$ oligomer toxicity is not dependent on massive tissue accumulation anymore but becomes effective as early as physiological $A \beta$ metabolism is disturbed at synaptic processes. The BAD hypothesis is compatible with all types of PSEN and APP-derived FAD mutations, which lead to either misregulation of $A \beta$ production and turnover, or an aberrant $\mathrm{A} \beta$ molecule, like Arctic mutation E22G (Pifer et al., 2011).

\section{Therapeutic Implications}

The advantage of the new BAD hypothesis in $\mathrm{AD}$ is to explain all major negative clinical results so far, while not restricted to the argument of too late treatment only. But more importantly, it guides into encouraging new future strategies.

Let us look into the unsuccessful history first. Table 3 summarizes predictions for clinical results following the two individual hypothesis.

\section{Why Secretase Inhibitors Failed in Clinical Trials}

The concept behind secretase inhibitors is to lower $A \beta$ production, thereby indirectly avoiding amyloid plaque formation. Two Gamma secretase inhibitors, semagacestat (Doody et al., 2013) and avagacestat (Coric et al., 2012), and at least three beta-secretase inhibitors, verubecestat (Egan et al., 2019), atabecestat (Timmers et al., 2018), and lanabecestat (Cebers et al., 2017), have been clinically tested. Two of them have not only found to be inactive but to create cognitive impairments. So far, the reasons for cognitive side effects have been discussed as individual structural issues caused by the compounds or by target-related side effects. In the case of semagacestat, the inhibition of Notch and the accumulation of the beta C-terminal fragment were claimed to be responsible for cognitive side effects (Doody et al., 2013). For BACE 1 inhibitors, it has been suggested that the synaptic plasticity via seizure protein 6 (SEZ6) is a possible reason for cognitive impairment (Zhu et al., 2018). According to the BAD hypothesis, it is an expected result as a consequence of chronic $A \beta$ monomer deficiency at synaptic sites. Following the BAD hypothesis, a Gamma secretase modulator rather than an inhibitor would be a possible treatment option, based on the fact that a decreased $\mathrm{A} \beta 42 / \mathrm{A} \beta 40$ ratio would lower the aggregation propensity, while essential overall $A \beta$ concentration could be maintained.

BACE elevation was always discussed as initial part of the pathology. It was not considered to be a consequence of a compensatory feedback. Following the BAD hypothesis, BACE is a good biomarker for $\mathrm{A} \beta$ pathology, but not a target for $\mathrm{AD}$ treatment.

\section{Why A $\beta$ Monomer-Directed Immunotherapies Failed in Clinical Trials}

Except for aducanumab (Sevigny et al., 2016), so far all clinically tested anti $A \beta$ antibodies engaged the excess $A \beta$ monomer. This violates the BAD hypothesis and should not contribute to tackle pathophysiology in $\mathrm{AD}$. On top of this hypothesis, also from a pharmacokinetic perspective, pan- $A \beta$ immunotherapy is practically impossible, since in the presence of excess $A \beta$ monomer in plasma and CSF in vivo, these antibodies would need unrealistic high doses to neutralize minor oligomer fraction next to high concentrations of monomer at neuronal synaptic sites. Even in clinically established antibody treatments for peripheral diseases, practical doses of therapeutic antibodies can only deal with low concentrations of proteins, e.g., interleukins, which persist in fairly low tissue and plasma concentrations even under pathophysiological conditions. An attempt to profile 
TABLE 2 | BAD vs. cascade hypothesis: key differences.

\begin{tabular}{|c|c|c|}
\hline Item & Beta amyloid cascade hypothesis & Beta amyloid dysfunction (BAD) hypothesis \\
\hline $\begin{array}{l}\text { Physiological } A \beta \\
\text { monomer }\end{array}$ & No function; source for aggregated $A \beta$ & To be preserved at adequate concentrations in synaptic processes \\
\hline Pathophysiology & Amyloid deposits (protofibrils, fibrils) & Misfolded species formed in neurons interfere immediately with default $A \beta$ processing \\
\hline $\begin{array}{l}\text { Reduced A } \beta \text { CSF } \\
\text { levels in AD }\end{array}$ & Difficult to explain & Benign CSF A $\beta$ monomer inversely correlates with early neurotoxic A $\beta$ oligomers \\
\hline APP KO mice & $\begin{array}{l}\text { Age dependent learning deficits indicate that } \\
\underline{\mathbf{A P P}} \text { is essential in synaptic processes }\end{array}$ & $\begin{array}{l}\text { Age dependent learning deficits indicate that } \underline{\boldsymbol{A} \beta} \underline{\text { monomer }} \text { is essential in synaptic } \\
\text { processes }\end{array}$ \\
\hline Genetic AD link in FAD & $\begin{array}{l}\text { Not all PSEN mutations explained by } A \beta \\
\text { overproduction }\end{array}$ & $\begin{array}{l}\text { All PSEN and APP mutations interfere with homeostasis of regular physiological } A \beta \\
\text { monomer }\end{array}$ \\
\hline
\end{tabular}

TABLE 3 | BAD vs. cascade hypothesis: prediction of clinical results for major therapeutic classes.

\begin{tabular}{|c|c|c|}
\hline Therapeutic class & $\begin{array}{l}\text { Beta amyloid cascade } \\
\text { hypothesis }\end{array}$ & Beta amyloid dysfunction (BAD) hypothesis \\
\hline Gamma-secretase inhibitors; & Efficacious & Not efficacious \\
\hline $\begin{array}{l}\text { BACE inhibitors; } \\
\text { Pan A } \beta \text { immunotherapy }\end{array}$ & Lower aggregation propensity & $\begin{array}{l}\text { Inferior with role of physiological } A \beta \text { in synaptic function; risk of cognitive deficits through lack of } \\
\text { physiological } A \beta \text { monomer at synaptic sites }\end{array}$ \\
\hline \multirow[t]{2}{*}{ Gamma-secretase modulator } & Partially efficacious & Efficacious \\
\hline & Insufficient target coverage & Reducing aggregation propensity while maintaining overall $A \beta$ monomer concentration \\
\hline \multirow{2}{*}{$\begin{array}{l}\text { Early misfolded } A \beta \text { oligomer } \\
\text { specific immunotherapy }\end{array}$} & Partially efficacious & Efficacious \\
\hline & Insufficient target coverage & $\begin{array}{l}\text { Neutralizing low fraction of pathogenic misfolded } A \beta \text { species generated during early impaired } \\
\text { neuronal } A \beta \text { processing is sufficient }\end{array}$ \\
\hline
\end{tabular}

the monomer and oligomer binding antibody crenezumab (Adolfsson et al., 2012) toward oligomer binding by raising the dose fourfold in Phase 3 after unsuccessful Phase 2 study was obviously not sufficient and failed. Hence, the oligomer hypothesis so far has not been tested by crenezumab.

\section{Why A $\beta$ Fibril-Directed Immunotherapies Failed in Clinical Trials}

Fibril-type $\mathrm{A} \beta$ in $\mathrm{AD}$ brain plaques are very late insoluble deposits formed by either addition of $A \beta$ monomer to a template or potential slow conversion of $A \beta$ oligomers. In any way, plaque load is not correlating well with cognitive impairment in AD (Terry et al., 1991; Aizenstein et al., 2008; Malek-Ahmadi et al., 2016). Therapeutically, solubilizing plaques also means to resolubilize inert fibril-type $A \beta$ with possible transient creation and release of soluble oligomers at unknown concentrations and sites and potential implications for the AD pathology.

A recent paper in 2019 has followed surviving AD patients who underwent dissolution of plaques in the course of the AN1792 active immunization study (Nicoll et al., 2019). They did not show significant cognitive improvement. While part of the reason might be late treatment, it can be assumed that the polyclonal antibody response elicited by aggregated $A \beta$ was $A \beta$ isoform unspecific.

\section{$A \beta$ Oligomer Neutralizing Treatments and Biomarker Options}

Future clinical candidates for prevention and treatment of $\mathrm{AD}$ should not only display high potency for all early misfolded
$\mathrm{A} \beta \mathrm{x}-\mathrm{y}$ oligomers, but also demonstrate at least 1000 -fold selectivity over $A \beta$ monomer and $A \beta$ fibrils. The best way to characterize potency and selectivity of candidate antibodies is immunoprecipitation of the majority of all $A \beta x-y$ species of misfolded and modified oligomers from post mortem AD brains under detergent and non-detergent conditions. Such antibodies have been described, e.g., 4D10 and similar globulomerderived antibodies (Hillen et al., 2010; Barghorn et al., 2011, 2012). Other groups describe the generation of $A \beta$ oligomer selective antibodies obtained by immunization with loop peptides (Gibbs et al., 2019).

Past clinical $A \beta$ projects were often selected and designed along the availability of target engagement biomarkers, which enabled go/no-go decision points after a short proof-of-concept study. Clinical studies with secretase inhibitors have generated conclusive results, since in vivo potency was clearly demonstrated by dose-dependent significant reduction of $A \beta$ levels in CSF. Future $A \beta$-related therapies in $A D$ need to be tailored to clear exclusively pathophysiology while seeking new opportunities for early target engagement biomarkers. The globulomer technology has also provided an active vaccination regimen using a thirdgeneration truncated globulomer mutant as antigen (Barghorn et al., 2016). The elicited polyclonal antibody response by these antigens is remarkably oligomer epitope specific.

An early biomarker concept to enable robust dose finding for $A \beta$ oligomer antibodies might be more challenging since $A \beta$ oligomers in CSF are, if at all, only present at extremely low concentrations. But in vivo $\mathrm{A} \beta$ kinetics measurements generated by clinical SILK technology (Patterson et al., 2015) offers an opportunity since it was shown to be dependent on age and AD 
status of patients and control subjects. In a clinical proof-ofconcept study, potent $A \beta$ oligomer selective antibodies should normalize $A \beta$ metabolism also in an acute or subacute setting using SILK. This approach could serve as a dose finding study to de-risk a subsequent pivotal 18-month study.

The BAD hypothesis also predicts BACE levels to be normalized in CSF as well as $\mathrm{A} \beta$ monomer upon treatment. Proof-of-concept studies can even be back-translated into APP TG mice, since BACE activity and substrates were shown to be technically measurable in CSF of mice (Dislich et al., 2015).

Following the BAD hypothesis, it will also be possible to select and optimize the best anti- $A \beta$ oligomer antibody treatments in $\mathrm{AD}$. A typical iterative procedure would be screening of antibodies in emerging ultrasensitive $A \beta$ oligomer CSF and blood tests. Those $A \beta$ oligomer selective antibodies that score best in neutralizing traces of residual $A \beta$ oligomers in brain extracts and CSF (Salvadores et al., 2014) should be preferred clinical candidates.

\section{The BAD Hypothesis Needs Further Refinement}

The newly introduced $\mathrm{BAD}$ hypothesis in $\mathrm{AD}$ is meant to start a fundamental re-thinking for future $A \beta$-related treatments. After clinical failure of major amyloid beta treatments, for the majority of scientists, investors, society, and patients, the $A \beta$ approach seems to be without a further perspective. Many companies and research institutions are turning away from the best validated target in $\mathrm{AD}$ without analyzing their basic mistakes in past strategies. Unfortunately, almost all clinical $A \beta$-related approaches so far seemed to be wrong, since they were targeting predominantly the physiology rather than the early pathophysiology of this challenging peptide.

The BAD hypothesis should encourage us to restart the clinical research with very different $A \beta$ approaches and immunotherapies in order to profile highly oligomer selective and potent treatments, which have already been preclinically described (Hillen et al., 2010; Barghorn et al., 2011, 2012, 2016).

\section{REFERENCES}

Abramov, E., Dolev, I., Fogel, H., Ciccotosto, G. D., Ruff, E., and Slutsky, I. (2009). Amyloid-beta as a positive endogenous regulator of release probability at hippocampal synapses. Nat. Neurosci. 12, 1567-1576. doi: 10.1038/nn. 2433

Adolfsson, O., Pihlgren, M., Toni, N., Varisco, Y., Buccarello, A. L., and Antoniello, K. (2012). An effector-reduced anti- $\beta$-amyloid (A $\beta$ ) antibody with unique $\mathrm{a} \beta$ binding properties promotes neuroprotection and glial engulfment of $\mathrm{A} \beta$. J. Neurosci. 32, 9677-9689. doi: 10.1523/JNEUROSCI.4742-11.2012

Aizenstein, H. J., Nebes, R. D., Saxton, J. A., Price, J. C., Mathis, C. A., and Tsopelas, N. D. (2008). Frequent amyloid deposition without significant cognitive impairment among the elderly. Arch. Neurol. 65, 1509-1517. doi: 10.1001/archneur.65.11.1509

Antonios, G., Saiepour, N., Bouter, Y., Richard, B. C., Paetau, A., and VerkkoniemiAhola, A. (2013). N-truncated Abeta starting with position four: early intraneuronal accumulation and rescue of toxicity using NT4X-167, a novel monoclonal antibody. Acta Neuropathol. Commun. 1:56. doi: 10.1186/20515960-1-56

Barghorn, S., Hillen, H., Striebinger, A., and Giaisi, S. (2016). Abbvie GmbHぬCoKG, Immunogenic Products Based on Mutein Amyloid $\beta$ Amino
The BAD hypothesis will gain further validity when the exact role of a steadily produced $A \beta$ monomer will be fully explored at the molecular level. Like for Tau and Synuclein, there should be a clear function for the highly regulated nascent $\mathrm{A} \beta$ monomer protein in the physiology of neuronal processes (Copani, 2017).

\section{CONCLUSION}

Until we know more about the molecular mechanisms for the involvement of $A \beta$ monomer in the neuronal SVC process, the current BAD hypothesis will help to guide the discovery, selection, and development of various $A \beta$ oligomertargeted drugs.

The holy grail will be a protective active vaccination regimen based on a surrogate antigen at minimal frequency, which elicits permanent specific humoral immune response directed to the early key misfolding $A \beta$ oligomer species. Through this way, the non-pathological default neuronal processing of $A \beta$ should be kept untouched and clean and not allow for pathological downstream processes like formation of aberrant Tau isoforms in neurons. The ultimate goal will be to protect adults at the age of 40 or even earlier by active vaccination with a suitable designed A $\beta$ antigen, e.g., as described in Barghorn et al. (2016), which elicits permanently low levels of endogenous anti-A $\beta$ oligomer directed antibodies.

To summarize, the BAD hypothesis explains negative clinical results of major $A \beta$-directed clinical studies so far and lays the ground for a paradigm shift for effective and selective $A \beta$ oligomer-related clinical prevention and hopefully treatment concepts in $\mathrm{AD}$.

\section{AUTHOR CONTRIBUTIONS}

$\mathrm{HH}$ wrote the manuscript.

Acid Sequences and Uses thereof WO2016005328. Wiesbaden, DE: Mainzer Straße.

Barghorn, S., Hillen, H., Striebinger, A., Giaisi, S., Ebert, U., and Benatuil, L. (2011). Abbvie GmbHぬCoKG, Amyloid-Beta Binding Proteins WO201130377. Wiesbaden, DE: Mainzer Straße.

Barghorn, S., Hillen, H., Striebinger, A., Giaisi, S., Ebert, U., and Hsieh, C. M. (2012). Abbvie GmbHぬCoKG, Amyloid-beta Binding Proteins WO2012024187. Wiesbaden, DE: Mainzer Straße.

Bateman, R. J., Munsell, L. Y., Morris, J. C., Swarm, R., Yarasheski, K. E., and Holtzman, D. M. (2006). Human amyloid-beta synthesis and clearance rates as measured in cerebrospinal fluid in vivo. Nat. Med. 12, 856-861. doi: 10.1038/ nm1438

Bayer, A. J., Bullock, R., Jones, R. W., Wilkinson, D., Paterson, K. R., and Jenkins, L. (2005). Evaluation of the safety and immunogenicity of synthetic Abeta42 (AN1792) in patients with AD. Neurology 64, 94-101. doi: 10.1212/01.WNL. 0000148604.77591 .67

Blennow, K., Dubois, B., Fagan, A. M., Lewczuk, P., de Leon, M. J., and Hampel, H. (2015). Clinical utility of cerebrospinal fluid biomarkers in the diagnosis of early Alzheimer's disease. Alzheimers Dement. 11, 58-69. doi: 10.1016/j.jalz.2014. 02.004 
Brody, D. L., Magnoni, S., Schwetye, K. E., Spinner, M. L., Esparza, T. J., and Stocchetti, N. (2008). Amyloid-beta dynamics correlate with neurological status in the injured human brain. Science 321, 1221-1224. doi: 10.1126/science. 1161591

Burré, J., Sharma, M., and Südhof, T. C. (2014). $\alpha$-Synuclein assembles into higher-order multimers upon membrane binding to promote SNARE complex formation. PNAS 111, E4274-E4283. doi: 10.1073/pnas.1416598111

Burré, J., Sharma, M., and Südhof, T. C. (2018). Cell Biology and Pathophysiology of $\alpha$-Synuclein. Cold Spring Harb. Perspect. Med. 8:a024091. doi: 10.1101/ cshperspect.a024091

Cebers, G., Alexander, R. C., Haeberlein, S. B., Han, D., Goldwater, R., and Ereshefsky, L. (2017). AZD3293: pharmacokinetic and pharmacodynamic effects in healthy subjects and patients with Alzheimer's disease. J. Alzheimers Dis. 55, 1039-1053. doi: 10.3233/JAD-160701

Cirrito, J. R., Kang, J. E., Lee, J., Stewart, F. R., Verges, D. K., Silverio, L. M., et al. (2008). Endocytosis is required for synaptic activity-dependent release of amyloid-beta in vivo. Neuron 58, 42-51. doi: 10.1016/j.neuron.2008.02.003

Cirrito, J. R., Yamada, K. A., Finn, M. B., Sloviter, R. S., Bales, K. R., and May, P. C. (2005). Synaptic activity regulates interstitial fluid amyloid-beta levels In vivo. Neuron 48, 913-922. doi: 10.1016/j.neuron.2005.10.028

Cline, E. N., Bicca, M. A., Viola, K. L., and Klein, W. L. (2018). The amyloid$\beta$ oligomer hypothesis: beginning of the third decade. J. Alzheimers Dis. 64, S567-S610. doi: 10.3233/JAD- 179941

Copani, A. (2017). The underexplored question of $\beta$-amyloid monomers. Eur. J. Pharmacol. 817, 71-75. doi: 10.1016/j.ejphar.2017.05.057

Coric, V., van Dyck, C. H., Salloway, S., Andreasen, N., Brody, M., and Richter, R. W. (2012). Safety and tolerability of the $\gamma$-secretase inhibitor avagacestat in a phase 2 study of mild to moderate Alzheimer disease. Arch. Neurol. 69, 1430-1440. doi: 10.1001/archneurol.2012.2194

Dawson, G. R., Seabrook, G. R., Zheng, H., Smith, D. W., Graham, S., and O’Dowd, G. (1999). Age-related cognitive deficits, impaired long-term potentiation and reduction in synaptic marker density in mice lacking the beta-amyloid precursor protein. Neuroscience 90, 1-13. doi: 10.1016/S0306-4522(98)00410-2

Decourt, B., and Sabbagh, M. N. (2011). BACE1 as a potential biomarker for Alzheimer's disease. J. Alzheimers Dis. 24(Suppl. 2), 53-59. doi: 10.3233/JAD2011- 110017

Deng, M., He, W., Tan, Y., Han, H., Hu, X., Xia, K., et al. (2013). Increased expression of reticulon 3 in neurons leads to reduced axonal transport of $\beta$ site amyloid precursor protein-cleaving enzyme 1. J. Biol. Chem. 288, 30236-30245. doi: 10.1074/jbc.M113.480079

Dislich, B., Wohlrab, F., Bachhuber, T., Müller, S. A., Kuhn, P. H., and Hogl, S. (2015). Label-free quantitative proteomics of mouse cerebrospinal fluid detects $\beta$-site app cleaving enzyme (BACE1) protease substrates In Vivo. Mol. Cell Proteomics 14, 2550-2563. doi: 10.1074/mcp.M114.041533

Doody, R. S., Aisen, P. S., and Iwatsubo, T. (2013). Semagacestat for treatment of Alzheimer's disease. N. Engl. J. Med. 369:1661. doi: 10.1056/NEJMc1310845

Dyrks, T., Weidemann, A., Multhaup, G., Salbaum, J. M., Lemaire, H. G., Kang, J., et al. (1988). Identification, transmembrane orientation and biogenesis of the amyloid A4 precursor of Alzheimer's disease. EMBO J. 4, 949-957. doi: 10.1002/j.1460-2075.1988.tb02900.x

Egan, M. F., Kost, J., Voss, T., Mukai, Y., Aisen, P. S., and Cummings, J. L. (2019). Randomized trial of verubecestat for prodromal Alzheimer's Disease. N. Engl. J. Med. 380, 1408-1420. doi: 10.1056/NEJMoa1812840

Fagan, A. M., Head, D., Shah, A. R., Marcus, D., Mintun, M., Morris, J. C., et al. (2009). Decreased cerebrospinal fluid Abeta(42) correlates with brain atrophy in cognitively normal elderly. Ann. Neurol. 65, 176-183. doi: 10.1002/ana. 21559

Fukumoto, H., Cheung, B. S., Hyman, B. T., and Irizarry, M. C. (2002). Betasecretase protein and activity are increased in the neocortex in Alzheimer disease. Arch. Neurol. 59, 1381-1389. doi: 10.1001/archneur.59.9.1381

Gellermann, G. P., Byrnes, H., Striebinger, A., Ullrich, K., and Mueller, R. (2008). Abeta-globulomers are formed independently of the fibril pathway. Neurobiol. Dis. 30, 212-220. doi: 10.1016/j.nbd.2008.01.010

Gibbs, E., Silverman, J. M., Zhao, B., Peng, X'., Wang, J., and Wellington, C. L. (2019). A Rationally Designed Humanized Antibody Selective for Amyloid Beta Oligomers in Alzheimer's Disease. Sci. Rep. 9:9870. doi: 10.1038/s41598-01946306-5
Giuffrida, M. L., Caraci, F., Pignataro, B., Cataldo, S., De Bona, P., and Bruno, V. (2009). Beta-amyloid monomers are neuroprotective. J. Neurosci. 29, 10582 10587. doi: 10.1523/JNEUROSCI.1736-09.2009

Glenner, G. G., and Wong, C. W. (1984). Alzheimer's disease: initial report of the purification and characterization of a novel cerebrovascular amyloid protein Biochem. Biophys. Res. Commun. 120, 885-890. doi: 10.1016/s0006-291x(84) 80190-4

Guo, T., Noble, W., and Hanger, D. P. (2017). Roles of tau protein in health and disease. Acta Neuropathol. 133, 665-704. doi: 10.1007/s00401-017-1707-9

Hardy, J. A., and Higgins, G. A. (1992). Alzheimer's disease: the amyloid cascade hypothesis. Science 256, 184-185. doi: 10.1126/science.1566067

Hillen, H., Barghorn, S., Striebinger, A., Labkovsky, B., Müller, R., and Nimmrich, V. (2010). Generation and therapeutic efficacy of highly oligomer-specific betaamyloid antibodies. J. Neurosci. 30, 10369-10379. doi: 10.1523/JNEUROSCI. 5721-09.2010

Holsinger, R. M., McLean, C. A., Beyreuther, K., Masters, C. L., and Evin, G. (2002). Increased expression of the amyloid precursor beta-secretase in Alzheimer's disease. Ann. Neurol. 51, 783-786. doi: 10.1002/ana.10208

Kamenetz, F., Tomita, T., Hsieh, H., Seabrook, G., Borchelt, D., Iwatsubo, T., et al. (2003). APP processing and synaptic function. Neuron 37, 925-937. doi: 10.1016/S0896-6273(03)00124-7

Klementieva, O., Willén, K., Martinsson, I., Israelsson, B., Engdahl, A., and Cladera, J. (2017). Pre-plaque conformational changes in Alzheimer's disease-linked A $\beta$ and APP. Nat. Commun. 8:14726. doi: 10.1038/ncomms 14726

Lauren, J., Gimbel, D. A., Nygaard, H. B., Gilbert, J. W., and Strittmatter, S. M. (2009). Cellular prion protein mediates impairment of synaptic plasticity by amyloid-beta oligomers. Nature 457, 1128-1132. doi: 10.1038/nature 07761

Li, R., Lindholm, K., Yang, L. B., Yue, X., Citron, M., and Yan, R. (2004). Amyloid beta peptide load is correlated with increased beta-secretase activity in sporadic Alzheimer's disease patients. Proc. Natl. Acad. Sci. U.S.A. 101, 3632-3637. doi: 10.1073/pnas.0205689101

Lu, J. X., Qiang, W., Yau, W. M., Schwieters, C. D., Meredith, S. C., and Tycko, R. (2013). Molecular structure of $\beta$-amyloid fibrils in Alzheimer's disease brain tissue. Cell 154, 1257-1268. doi: 10.1016/j.cell.2013.08.035

Malek-Ahmadi, M., Perez, S. E., Chen, K., and Mufson, E. J. (2016). Neuritic and diffuse plaque associations with memory in non-cognitively impaired elderly. J. Alzheimers Dis. 53, 1641-1652. doi: 10.3233/JAD-160365

Masters, C. L., Simms, G., Weinman, N. A., Multhaup, G., McDonald, B. L., and Beyreuther, K. (1985). Amyloid plaque core protein in Alzheimer disease and down syndrome. Proc. Natl. Acad. Sci. U.S.A. 82, 4245-4249. doi: 10.1073/pnas. 82.12.4245

Morgan, C., Colombres, M., Nuñez, M. T., and Inestrosa, N. C. (2004). Structure and function of amyloid in Alzheimer's disease. Prog. Neurobiol. 74, 323-349. doi: 10.1016/j.pneurobio.2004.10.004

Morley, J. E., Farr, S. A., Banks, W. A., Johnson, S. N., Yamada, K. A., and Xu, L. (2010). A physiological role for amyloid-beta protein:enhancement of learning and memory. J. Alzheimers Dis. 19, 441-449. doi: 10.3233/JAD-2009-1230

Morton, R. A., Kuenzi, F. M., Fitzjohn, S. M., Rosahl, T. W., Smith, D., and Zheng, H. (2002). Impairment in hippocampal long-term potentiation in mice underexpressing the Alzheimer's disease related gene presenilin-1. Neurosci. Lett. 319, 37-40. doi: 10.1016/S0304-3940(01)02512-5

Müller, U. C., Deller, T., and Korte, M. (2017). Not just amyloid: physiological functions of the amyloid precursor protein family. Nat. Rev. Neurosci. 18, 281-298. doi: 10.1038/nrn.2017.29

Nicoll, J. A. R., Buckland, G. R., Harrison, C. H., Page, A., Harris, S., and Love, S. (2019). Persistent neuropathological effects 14 years following amyloid- $\beta$ immunization in Alzheimer's disease. Brain. doi: 10.1093/brain/awz142 [Epub ahead of print]

Ohnishi, T., Yanazawa, M., Sasahara, T., Kitamura, Y., Hiroaki, H., and Fukazawa, Y. (2015). Na, K-ATPase alpha3 is a death target of Alzheimer patient amyloidbeta assembly. Proc. Natl. Acad. Sci. U.S.A. 112, E4465-E4474. doi: 10.1073/ pnas. 1421182112

Oldfield, C. J., and Dunker, A. K. (2014). Intrinsically disordered proteins and intrinsically disordered protein regions. Annu. Rev. Biochem. 83, 553-584. doi: 10.1146/annurev-biochem-072711-164947 
Ovsepian, S. V., O’Leary, V. B., Zaborszky, L., Ntziachristos, V., and Dolly, J. O. (2018). Synaptic vesicle cycle and amyloid $\beta$ : biting the hand that feeds. Alzheimers Dement. 4, 502-513. doi: 10.1016/j.jalz.2018.01.011

Panza, F., Lozupone, M., Solfrizzi, V., Sardone, R., Piccininni, C., and Dibello, V. (2018). BACE inhibitors in clinical development for the treatment of Alzheimer's disease. Expert Rev. Neurother. 18, 847-857. doi: 10.1080/14737175. 2018.1531706

Patterson, B. W., Elbert, D. L., Mawuenyega, K. G., Kasten, T., Ovod, V., Ma, S., et al. (2015). Age and amyloid effects on human central nervous system amyloid-beta kinetics. Ann. Neurol. 78, 439-453. doi: 10.1002/ana.24454

Petkova, A. T., Ishii, Y., Balbach, J. J., Antzutkin, O. N., Leapman, R. D., and Delaglio, F. (2002). A structural model for Alzheimer's beta -amyloid fibrils based on experimental constraints from solid state NMR. Proc. Natl. Acad. Sci. U.S.A. 99, 16742-16747. doi: 10.1073/pnas.262663499

Philipson, O., Lannfelt, L., and Nilsson, L. (2009). Genetic and pharmacological evidence of intraneuronal $\mathrm{A} \beta$ accumulation in APP transgenic mice. FEBS Lett. 583, 3021-3026. doi: 10.1016/j.febslet.2009.08.009

Pifer, P. M., Yates, E. A., and Legleiter, J. (2011). Point mutations in A $\beta$ result in the formation of distinct polymorphic aggregates in the presence of lipid bilayers. PLoS One 6:e16248. doi: 10.1371/journal.pone.0016248

Plant, L. D., Boyle, J. P., Smith, I. F., Peers, C., and Pearson, H. A. (2003). The production of amyloid beta peptide is a critical requirement for the viability of central neurons. J. Neurosci. 23, 5531-5535. doi: 10.1523/JNEUROSCI.23-1305531.2003

Reddy, P. H., and Beal, M. F. (2008). Amyloid beta, mitochondrial dysfunction and synaptic damage: implications for cognitive decline in aging and Alzheimer's disease. Trends Mol. Med. 14, 45-53. doi: 10.1016/j.molmed.2007. 12.002

Rosén, C., Hansson, O., Blennow, K., and Zetterberg, H. (2013). Fluid biomarkers in Alzheimer's disease - current concepts. Mol. Neurodegener. 8:20. doi: 10.1186/ 1750-1326-8-20

Salvadores, N., Shahnawaz, M., Scarpini, E., Tagliavini, F., and Soto, C. (2014). Detection of misfolded $A \beta$ oligomers for sensitive biochemical diagnosis of Alzheimer's disease. Cell Rep. 7, 261-268. doi: 10.1016/j.celrep.2014.02.031

Seabrook, G. R., Smith, D. W., Bowery, B. J., Easter, A., Reynolds, T., and Fitzjohn, S. M. (1999). Mechanisms contributing to the deficits in hippocampal synaptic plasticity in mice lacking amyloid precursor protein. Neuropharmacology 38 , 349-359. doi: 10.1016/S0028-3908(98)00204-4

Sevigny, J., Chiao, P., Bussière, T., Weinreb, P. H., Williams, L., and Maier, M. (2016). The antibody aducanumab reduces $A \beta$ plaques in Alzheimer's disease. Nature 537, 50-56. doi: 10.1038/nature19323

Smith, L. M., and Strittmatter, S. M. (2017). Binding Sites for Amyloid- $\beta$ Oligomers and Synaptic Toxicity. Cold Spring Harb. Perspect. Med. 7:a024075. doi: 10. 1101/cshperspect.a024075

St George-Hyslop, P. H., and Petit, A. (2005). Molecular biology and genetics of Alzheimer's disease. C R Biol. 328, 119-130. doi: 10.1016/j.crvi.2004.10.013

Steuble, M., Diep, T. M., Schätzle, P., Ludwig, A., Tagaya, M., and Kunz, B. (2012). Calsyntenin-1 shelters APP from proteolytic processing during anterograde axonal transport. Biol. Open 1, 761-774. doi: 10.1242/bio.20121578

Südhof, T. C. (1995). The synaptic vesicle cycle: a cascade of protein-protein interactions. Nature 375, 645-653. doi: 10.1038/375645a0

Terry, R. D., Masliah, E., Salmon, D. P., Butters, N., DeTeresa, R., and Hill, R. (1991). Physical basis of cognitive alterations in Alzheimer's disease: synapse loss is the major correlate of cognitive impairment. Ann. Neurol. 30, 572-580. doi: 10.1002/ana.410300410

Thinakaran, G., and Koo, E. H. (2008). Amyloid precursor protein trafficking, processing, and function. J. Biol. Chem. 283, 29615-29619. doi: 10.1074/jbc. R800019200

Timmers, M., Streffer, J. R., Russu, A., Tominaga, Y., Shimizu, H., and Shiraishi, A. (2018). Pharmacodynamics of atabecestat (JNJ-54861911), an oral BACE1 inhibitor in patients with early Alzheimer's disease: randomized, double-blind, placebo-controlled study. Alzheimers Res. Ther. 10:85. doi: 10.1186/s13195018-0415-6

Vassar, R., Bennett, B. D., Babu-Khan, S., Kahn, S., Mendiaz, E. A., and Denis, P. (1999). Beta-secretase cleavage of Alzheimer's amyloid precursor protein by the transmembrane aspartic protease BACE. Science 286, 735-741. doi: 10.1126/ science.286.5440.735

Weggen, S., and Beher, D. (2012). Molecular consequences of amyloid precursor protein and presenilin mutations causing autosomal-dominant Alzheimer's disease. Alzheimers Res. Ther. 4:9. doi: 10.1186/alzrt107

Wolfe, M. S., Xia, W., Ostaszewski, B. L., Diehl, T. S., Kimberly, W. T., and Selkoe, D. J. (1999). Two transmembrane aspartates in presenilin-1 required for presenilin endoproteolysis and gamma-secretase activity. Nature 398, 513-517. doi: $10.1038 / 19077$

Yan, S. D., Chen, X., Fu, J., Chen, M., Zhu, H., Roher, A., et al. (1996). RAGE and amyloid-beta peptide neurotoxicity in Alzheimer's disease. Nature 382, 685-691.

Yang, T., O’Malley, T. T., Kanmert, D., Jerecic, J., Zieske, L. R., Zetterberg, H., et al. (2015). A highly sensitive novel immunoassay specifically detects low levels of soluble $\mathrm{A} \beta$ oligomers in human cerebrospinal fluid. Alzheimer's Res. Ther. 7:14. doi: 10.1186/s13195-015-0100-y

Youmans, K. L., Tai, L. M., Kanekiyo, T., Stine, W. B. Jr., Michon, S. C., and Nwabuisi-Heath, E. (2012). Intraneuronal A $\beta$ detection in 5xFAD mice by a new A $\beta$-specific antibody. Mol. Neurodegener. 7:8. doi: 10.1186/1750$1326-7-8$

Yu, L., Edalji, R., Harlan, J. E., Holzman, T. F., Lopez, A. P., and Labkovsky, B. (2009). Structural characterization of a soluble amyloid beta-peptide oligomer. Biochemistry 48, 1870-1877. doi: 10.1021/bi802046n

Zetterberg, H., Andreasson, U., Hansson, O., Wu, G., Sankaranarayanan, S., and Andersson, M. E. (2008). Elevated cerebrospinal fluid BACE1 activity in incipient Alzheimer disease. Arch. Neurol. 65, 1102-1107. doi: 10.1001/ archneur.65.8.1102

Zhang, X. M., Cai, Y., Xiong, K., Cai, H., Luo, X. G., and Feng, J. C. (2009). Beta-secretase-1 elevation in transgenic mouse models of Alzheimer's disease is associated with synaptic/axonal pathology and amyloidogenesis: implications for neuritic plaque development. Eur. J. Neurosci. 30, 2271-2283. doi: 10.1111/ j.1460-9568.2009.07017.x

Zhao, W., Dumanis, S. B., Tamboli, I. Y., Rodriguez, G. A., Jo Ladu, M., Moussa, C. E., et al. (2014). Human APOE genotype affects intraneuronal A $\beta 1$ 42 accumulation in a lentiviral gene transfer model. Hum. Mol. Genet. 23, 1365-1375. doi: 10.1093/hmg/ddt525

Zhong, Z., Ewers, M., Teipel, S., Bürger, K., Wallin, A., and Blennow, K. (2007). Levels of beta-secretase (BACE1) in cerebrospinal fluid as a predictor of risk in mild cognitive impairment. Arch. Gen. Psychiatry 64, 718-726. doi: 10.1001/ archpsyc.64.6.718

Zhu, K., Xiang, X., Filser, S., Marinković, P., Dorostkar, M. M., and Crux, S. (2018). Beta-site amyloid precursor protein cleaving enzyme 1 inhibition impairs synaptic plasticity via seizure protein 6. Biol. Psychiatry 83, 428-437. doi: 10. 1016/j.biopsych.2016.12.023

Conflict of Interest: The author declares that the research was conducted in the absence of any commercial or financial relationships that could be construed as a potential conflict of interest.

Copyright $\odot 2019$ Hillen. This is an open-access article distributed under the terms of the Creative Commons Attribution License (CC BY). The use, distribution or reproduction in other forums is permitted, provided the original author(s) and the copyright owner(s) are credited and that the original publication in this journal is cited, in accordance with accepted academic practice. No use, distribution or reproduction is permitted which does not comply with these terms. 